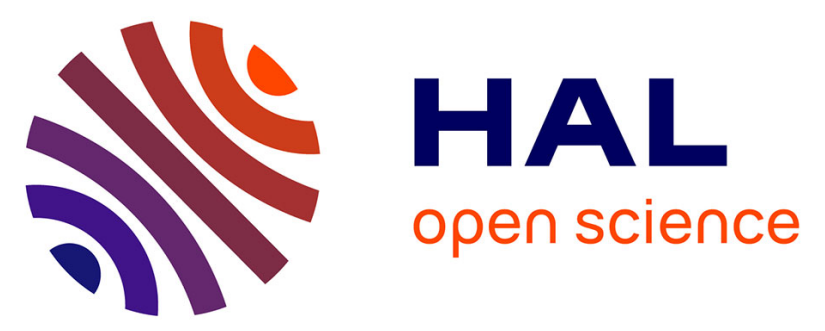

\title{
Impact of Airborne Particle Size, Acoustic Airflow and Breathing Pattern on Delivery of Nebulized Antibiotic into the Maxillary Sinuses Using a Realistic Human Nasal Replica
}

Lara Leclerc, Jérémie Pourchez, Gérald Aubert, Sandrine Leguellec, Laurent Vecellio, Michèle Cottier, Marc Durand

\section{To cite this version:}

Lara Leclerc, Jérémie Pourchez, Gérald Aubert, Sandrine Leguellec, Laurent Vecellio, et al.. Impact of Airborne Particle Size, Acoustic Airflow and Breathing Pattern on Delivery of Nebulized Antibiotic into the Maxillary Sinuses Using a Realistic Human Nasal Replica. Pharmaceutical Research, 2014, 31 (9), pp.2335-2343. 10.1007/s11095-014-1330-6 . emse-01110944

\section{HAL Id: emse-01110944 \\ https://hal-emse.ccsd.cnrs.fr/emse-01110944}

Submitted on 16 Oct 2015

HAL is a multi-disciplinary open access archive for the deposit and dissemination of scientific research documents, whether they are published or not. The documents may come from teaching and research institutions in France or abroad, or from public or private research centers.
L'archive ouverte pluridisciplinaire HAL, est destinée au dépôt et à la diffusion de documents scientifiques de niveau recherche, publiés ou non, émanant des établissements d'enseignement et de recherche français ou étrangers, des laboratoires publics ou privés. 


\section{Impact of airborne particle size, acoustic airflow and breathing pattern on delivery of nebulized antibiotic into the maxillary sinuses using a realistic human nasal replica}

Lara Leclerc, Jérémie Pourchez, Gérald Aubert, Sandrine Leguellec, Laurent Vecellio, Michèle Cottier, Marc Durand

Lara Leclerc, Michèle Cottier, Marc Durand

Université Jean Monnet F-42023, Saint-Etienne, France, LINA EA 4624

Lara Leclerc, Jérémie Pourchez

Ecole Nationale Supérieure des Mines, CIS-EMSE, LINA EA 4624, F-42023 Saint-Etienne, France

Lara Leclerc, Jérémie Pourchez, Michèle Cottier, Marc Durand

SFR IFRESIS, F-42023, Saint-Etienne, France

Gérald Aubert

CHU Saint-Etienne, Antibiology Department, F-42023, Saint-Etienne, France

Sandrine Leguellec, Laurent Vecellio

Centre d'Etudes des Pathologies Respiratoires INSERM U1100/EA 6305, Faculté de Médecine, Université François Rabelais, Tours, France

DTF Aerodrug, Faculté de Médecine, Université François Rabelais, Tours, France 
Marc Durand

Centre Hospitalier Emile Roux, ENT Department, F-43012, Le Puy en Velay, France

Suggested running head: Delivery of nebulized antibiotic into maxillary sinuses

Corresponding author:

Lara Leclerc

Laboratoire Interdisciplinaire d'étude des Nanoparticules Aérosolisées (LINA - EA 4624)

Faculté de Médecine Jacques Lisfranc, Université Jean Monnet

15 rue Ambroise Paré, 42023 Saint-Etienne cedex, France

Tel./fax: + 33477421443 / +3347742 14 94, mail: lara.leclerc@univ-st-etienne.fr or

$\underline{\text { leclerc@emse.fr }}$ 


\section{ABSTRACT}

\section{Purpose}

Improvement of clinical outcome in patients with sinuses disorders involves targeting delivery of nebulized drug into the maxillary sinuses. We investigated the impact of nebulization conditions (with and without $100 \mathrm{~Hz}$ acoustic airflow), particle size $(9.9 \mu \mathrm{m}, 2.8 \mu \mathrm{m}, 550 \mathrm{~nm}$ and $230 \mathrm{~nm}$ ) and breathing pattern (nasal vs. no nasal breathing) on enhancement of aerosol delivery into the sinuses using a realistic nasal replica developed by our team.

\section{Methods}

After segmentation of the airways by means of high-resolution computed tomography scans, a well-characterized nasal replica was created using a rapid prototyping technology.

A total of 168 intrasinus aerosol depositions were performed with changes of aerosol particle size and breathing patterns under different nebulization conditions using gentamicin as a marker.

\section{Results}

The results demonstrate that the fraction of aerosol deposited in the maxillary sinuses is enhanced by use of submicrometric aerosols, e.g. $8.155 \pm 1.476 \mathrm{mg} / \mathrm{L}$ of gentamicin in the left maxillary sinus for the $2.8 \mu \mathrm{m}$ particles vs. $2.056 \pm 0.0474$ for the $550 \mathrm{~nm}$ particles. Utilization of $100-\mathrm{Hz}$ acoustic airflow nebulization also produced a 2- to 3-fold increase in drug deposition in the maxillary sinuses (e.g. $8.155 \pm 1.476$ vs. $3.990 \pm 1.690$ for the $2.8 \mu \mathrm{m}$ particles).

\section{Conclusion}

Our study clearly shows that optimum deposition was achieved using submicrometric particles and $100-\mathrm{Hz}$ acoustic airflow nebulization with no nasal breathing. It is hoped that our new respiratory nasal replica will greatly facilitate the development of more effective delivery systems in the future. 


\section{KEY WORDS}

Aerosol therapy, drug deposition, nasal replica, maxillary sinuses 


\section{INTRODUCTION}

Health problems caused by rhinosinusitis constitute a considerable financial burden on society $(1,2)$. Blockage of sinus drainage through infection of the nasal mucosa or impaired mucociliary clearance produces a favorable environment for sinusitis in which pathogens may proliferate. Better targeting of delivery of nebulized antibiotics to the maxillary sinuses could improve clinical outcomes in patients with chronic rhinosinusitis disorders. However, such targeting is complex due to the anatomical features of the maxillary sinuses. These cavities are poorly ventilated and only communicate with the nasal fossa via the maxillary ostium, a narrow duct (about $1-5 \mathrm{~mm}$ in diameter; $10-15 \mathrm{~mm}$ in length) (3). Drug aerosolization is a common therapeutic approach in the treatment of sinuses disorders such as rhinosinusitis since it is painless and safe and offers a number of advantages over systemic therapy $(4,5)$. Several studies have demonstrated clinical benefits (6), although the question has not been extensively clinically investigated.

In this context, it is clearly of interest to achieve a better understanding of any nebulization features allowing specific targeting of the maxillary sinuses while avoiding pulmonary deposition, since the latter involves a risk of side effects. However, the nebulization conditions required to enhance aerosol deposition in the sinuses are not well established (7). For example, particles larger than $10 \mu \mathrm{m}$ inhaled nasally are known to be deposited in the nasal cavities (FDA guidance, 2002) but no international consensus or guidelines exist regarding the relationship between aerosol characteristics and precise deposition site within the nasal cavities such as the sinuses.

Human intranasal deposition studies are restricted by the risks associated with exposure and by ethical considerations. As an alternative, anatomical models have been proposed, such as cadaver heads $(8,9)$, nasal cavity replicas $(10,11)$ and nasal casts using recent prototyping 
techniques [fused deposition modeling (FDM) and stereolithography (e.g. the SLA, Viper or SAINT models)] $(12,13)$. While in vitro studies have shown that nebulized particles may be deposited in the paranasal sinuses, this is always at low concentrations due to ostium morphology as well as aerosol characteristics such as size, pressure and flow rate (14-18). Moreover, in a recent study we demonstrated a significant increase in intrasinus drug deposition using acoustic airflow nebulization $(100 \mathrm{~Hz})$ of micrometric airborne particles (9).

The aim of this study is to provide a better understanding of the parameters that enable specific drug targeting of the maxillary sinuses. To that end, we assessed and quantified the deposition of gentamicin (aminoglycoside antibiotic, used as a marker) as a function of variations in three nebulization parameters: airborne particle size within the micron and submicron range (230 $\mathrm{nm}$ to $9.9 \mu \mathrm{m}), 100 \mathrm{~Hz}$ acoustic airflow, and nasal or non-nasal breathing. The experiments were performed on a realistic nasal replica built using a stereolithography technique. 


\section{MATERIALS AND METHODS}

\section{Nasal replica}

Plastination allows anatomical specimens to be preserved in a physical state approaching that of live physiological conditions with numerous advantages (19). In particular, in plastinated head specimens, anatomical and aerodynamic behavior closely resembles patterns seen in vivo. Moreover, such models have a specific lateral-paramedian section providing easy access to the maxillary sinuses. Such plastinated human specimens were previously characterized anatomically, geometrically and aerodynamically (20) and then used for aerosol deposition studies (9). However, the main limitations of previous specimens of this type were the complexity of the washing steps involved, especially the long drying time (around 2 days) and the time required to obtain specimens (6 months). To overcome these drawbacks, a nasal replica of the human plastinated specimen was created for this study using a stereolithography technique.

First, a precise CT-scan of the plastinated model was obtained (LightSpeed VCT scanner, GE Healthcare, Milwaukee, Illinois, US). 226 DICOM scan images of the CT-scan, corresponding to the entire nasal cavities, were processed using HYCAD software to delimit the outlines of the cavities of interest, namely the frontal, ethmoidal and maxillary sinuses and the nasal fossae. Special care was taken in delineating the ostia, which constitute a critical ventilation pathway. The 226 segmented images were then converted and imported into the SolidWorks ${ }^{\circledR}$ software, a mechanical 3D computer-aided design program. The model was reconstructed step by step in 3D, as shown in Figure 1, and the replica was then manufactured in transparent, water-resistant, non-porous resin.

Endoscopy and CT scans were performed on the replica in order to assess the anatomical reproducibility of the known human plastinated model. Precise measurements were compared for the critical anatomical regions of the ostia and maxillary sinuses. 


\section{Nebulization systems and aerosol characterization}

Micrometric, submicrometric and nanometric aerosols were generated using the following medical jet nebulizers: an Atomisor NL20 (DTF Medical, France) and an Atomisor NL11 (DTF Medical, France), a modified SideStream (Philips Respironics, Ref 12NEB400, England), and a Nanoneb (DTF Medical, France). Aerosol particle sizes were expressed as mass median aerodynamic diameter (MMAD) using an electrical low-pressure impactor (ELPI, Dekati Ltd., Finland), as described in a previous study (9).

Aerosol characterization was performed using a chemical tracer, sodium fluoride $(\mathrm{NaF} ; 2.5$ $\mathrm{wt} \% ; 4 \mathrm{~mL}$ ), as recommended in a European standard (NF EN 13544-1). Operating at an airflow of 10 L.min ${ }^{-1}$, the ELPI allowed nebulized particles to be sorted into 12 size groups (7 $\mathrm{nm}$ to $10 \mathrm{~nm})$. The nebulizer was connected to the ELPI via a metal United States Pharmacopeia (USP) like artificial throat (height $112 \mathrm{~mm}$; width $42 \mathrm{~mm}$; internal diameter 19 $\mathrm{mm}$ ). NaF was aerosolized by the nebulizer for $10 \mathrm{~min}$, after which the various elements (USP throat and each stage) were rinsed with $5 \mathrm{~mL}$ of deionized water. The NaF concentration of samples was assayed by electrochemical means $\left(\right.$ PerfectION $^{\mathrm{TM}}$ combined with a SevenGo pro $^{\mathrm{TM}} \mathrm{F}-$ electrode, Mettler Toledo, France). Finally, the MMAD and the geometric standard deviation (GSD) of the nebulized particles were calculated using the electrochemical $\mathrm{NaF}$ measurements.

\section{Emitted aerosol fraction (output)}

The quantity of aerosol produced by the nebulizer over a 10-minute period was measured using a residual gravimetric method (21). The mass of gentamicin was measured on a filter before and after nebulization. The results were expressed as the percentage and as the actual mass of gentamicin collected. 


\section{Aerosol inhalation}

The experimental set-up is described on Figure 2 and comprised a nebulizer linked to nasal replica nostrils by a nasal plug (C28, medium size, DTF Medical, France) of a type used in clinical practice. The trachea of the nasal replica was connected to a respiratory pump (Pari, Compas II) allowing reproduction of various sinusoidal breathing patterns. A system of valves was used with the respiratory pump and the nasal cast to simulate different breathing patterns. A filter was connected to the trachea of the nasal cast to measure the amount of aerosol penetrating into the lung model (Inhalation Filter Pad, Pari GmbH, Germany).

An aminoglycoside antibiotic (gentamicin) was used as the marker (Gentamicin Panpharma, 80 mg/mL, CIP: 3400935120540, Exp: 03/2014, Batch 10267). In each experiment, $4 \mathrm{~mL}$ of gentamicin at a concentration of $80 \mathrm{mg} / \mathrm{mL}$ was nebulized for 10 minutes.

The nebulization systems were used with an AOLH ${ }^{\circledR}$ air source compressor (Diffusion Technique Française, DTF Medical, Saint-Etienne, France). This compressor can produce a "sonic aerosol" by adding a $100 \mathrm{~Hz}$ acoustic airflow during aerosol production as described previously (9). Each experiment was performed both with and without $100 \mathrm{~Hz}$ acoustic airflow.

\section{Breathing patterns}

- Normal nasal breathing: a cycle was defined as 15 breaths per minute, with a tidal volume (Vt) of $500 \mathrm{~mL}$, extrathoracic dead space of $21 \mathrm{ml}$, tracheal diameter of $1 \mathrm{~cm}$, principal bronchial diameter of $0.8 \mathrm{~cm}$ and inspiratory-to-expiratory time ratio (I:E) of 40/60. Under these conditions, inhalation time was set at 1.6 seconds and exhalation time was set at 2.4 seconds. These breathing parameters correspond to the reference physiological parameters for male adults (22-24). 
- Slow nasal breathing: a cycle was defined as a breathing rate of 10 breaths per minute and a Vt of $750 \mathrm{~mL}$. Under these conditions, inhalation time was set at 2.4 seconds and exhalation time at 3.6 seconds. Vt values were increased to avoid simulated hypoventilation.

For normal and slow nasal breathing, the set-up simulated inhalation through the nose and expiration through the mouth during operation of the respiratory pump.

- No nasal breathing: we compared nebulization without nasal breathing. The same experimental set-up was used but without any cycles. This experimental condition mimics inhalation and exhalation by the mouth.

\section{Drug deposition in the maxillary sinuses}

After nebulization, gentamicin was collected from each maxillary sinus by flushing 3 times with the same saline solution using a $1 \mathrm{~mL}$ syringe as previously described (9). Gentamicin concentrations in samples were quantified by fluorescence polymerization immunoassay (FPIA) with a TDxFLx ${ }^{\circledR}$ analyzer (Abbott Diagnostics Division, USA), which has a lower detection limit of $0.2 \mathrm{mg} / \mathrm{L}$. After recovery, the nasal replica was washed copiously with tap water and dried with pulsed air. Control nebulizations were performed with saline solution.

\section{Statistical analysis}

Analysis was performed and graphs plotted using Prism 5.0 software (GraphPad, San Diego, CA). Significance $(* * *)$ was established by ANOVA test $(\mathrm{p}<0.05)$. 


\section{RESULTS}

\section{Anatomical features of the nasal replica}

Nasofibroscopy showed that the nasal replica obtained by stereolithography was similar to the original plastinated human specimen. Endoscopic observations demonstrated good preservation of nasal airway anatomy in the nasal replica. Moreover, physical measurements of the replica confirmed exact reproduction of the plastinated model with a mean error of less than $0.3 \mathrm{~mm}$. For example, between the distance between the right and left sinuses for the plastinated model was $90.88 \mathrm{~mm}$ vs. $90.51 \mathrm{~mm}$ for the nasal replica, and $8.35 \mathrm{~mm}$ for the septum in the plastinated nasal septum vs. $8.90 \mathrm{~mm}$ for the nasal replica. All dimensions were well-respected, especially in such critical anatomical regions as the ostia of the maxillary sinuses.

Imaging data from CT scans confirmed high preservation of anatomy, particularly regarding the nasal airway and turbinate mucosa, which were as close as possible to actual physiological conditions. Figure 3 compares images of the left and right ostia in the plastinated specimen and the nasal replica where the measurements of the structures in the images were identical between the two models. Like the plastinated specimen $(9,20)$, the plastic nasal replica exhibits differences in the dimensions of the individual maxillary ostia: $6 \mathrm{~mm}$ long with a diameter of $2 \mathrm{~mm}$ for the right maxillary sinus ostium (normal anatomical form: long and narrow) and $2 \mathrm{~mm}$ long with a diameter of $5 \mathrm{~mm}$ for the left maxillary ostium (abnormally short and broad). These CT and endoscopy results confirm the good preservation of the anatomical and geometrical details in the model, enabling comparison to be made in this study between two different types of ostia morphology.

We earlier determined the reliability of airway geometry (using acoustic rhinometry) and airflow resistance (measured by rhinomanometry) in the plastinated model used as the basis 
for the stereolithographic nasal replica (20). Taking into account all of these elements, the nasal replica manufactured by stereolithography appeared anatomically, geometrically and aerodynamically similar to the original human plastinated specimen, which is a well-validated model of a healthy subject without nasal congestion.

\section{Aerosol particle size and emitted aerosol fraction}

The results are shown in Table I.

Each type of nebulizer had its own specific aerosol MMAD: $9.9 \mu \mathrm{m}$ for the Atomisor NL20 (GSD of 2), $2.8 \mu \mathrm{m}$ for the Atomisor NL11 (GSD of 3.2), $550 \mathrm{~nm}$ for the Sidestream (GSD of 2.1) and $230 \mathrm{~nm}$ for the Nanoneb (GSD of 1.6).

The emitted aerosol fraction was different for each type of nebulizer: $6.84 \pm 0.29 \%$ for the Atomisor NL20, $9.96 \pm 1.72 \%$ for the Atomisor NL11, $2.06 \pm 0.46 \%$ for the Sidestream and $0.26 \pm 0.04 \%$ for the Nanoneb.

\section{Drug deposition in the maxillary sinuses}

All results for gentamicin collected in the maxillary sinuses $(\mathrm{mg} / \mathrm{L}$ and percentage of the emitted dose) under each test condition (particle size, $100 \mathrm{~Hz}$ acoustic effect and breathing pattern) are summarized in two tables in the Supplementary Data section.

\section{Impact of anatomy}

Aerosols penetrate the maxillary sinuses with different gentamicin deposition profiles due to the anatomical features of the maxillary ostium (Figure $4 \mathrm{~A}$ and B). The amount of nebulized active substance collected in the left sinus of the nasal replica was consistently significantly higher for each type of nebulizer in accordance with the morphological differences of the ostia explained in the previous paragraph. These results are perfectly consistent with our 
previous study (9), and we again confirmed that the airflow resistance associated with the endonasal anatomy has a huge impact on drug deposition in the maxillary sinuses.

\section{Impact of nebulized particle size}

The impact of airborne particle size (different MMAD values) is clearly discernible in Figure 4. Data obtained for the $230 \mathrm{~nm}$ size are not exposed on the graphic because values are very close from the detection limit. Since the impact of particle size in aerosols is closely linked to the emitted aerosol fraction, the results shown in Figure 4A are expressed as percentage of emitted aerosol. We clearly demonstrated that deposition in the maxillary sinuses is enhanced for the smallest particle sizes for a normalized emitted aerosol fraction. Under these conditions, optimal results were obtained with the $230-\mathrm{nm}$ nebulizer, particularly in the left maxillary sinus.

Figure $4 \mathrm{~B}$ expresses the results in terms of the amount of gentamicin collected in the maxillary sinuses in $\mathrm{mg} / \mathrm{L}$. The Nanoneb nebulizer generated particles of around $230 \mathrm{~nm}$ and the gentamicin collected in the maxillary sinuses was between 0.2 and $0.4 \mathrm{mg} / \mathrm{L}$, which is very close to the control values (around $0.2 \mathrm{mg} / \mathrm{L}$ ). The SideStream nebulizer generated particles of around $550 \mathrm{~nm}$ and the maximum mean quantity of gentamicin deposited was close to $2 \mathrm{mg} / \mathrm{L}$. Use of larger particles appeared to enhance drug deposition in the maxillary sinuses, with the amount of gentamicin collected for the NL11 nebulizer reaching a mean maximum of $10 \mathrm{mg} / \mathrm{L}$. Finally, the largest particles generated by the NL20 nebulizer $(9.9 \mu \mathrm{m})$ were deposited to a lesser extent than the $2.8-\mu \mathrm{m}$ particles (maximum of $2 \mathrm{mg} / \mathrm{L}$ in the left maxillary sinus). Under these conditions, using current nebulization technologies, the particles most efficiently deposited in the maxillary sinuses in terms of mass are those measuring 2.8 $\mu \mathrm{m}$. 


\section{Impact of breathing patterns}

Figure 5 shows the results for the SideStream and the NL11 nebulizers under normal nasal breathing and non-nasal breathing conditions. No significant differences were noted between normal and slow nasal breathing for the various types of nebulizers (data not shown). By contrast, intrasinus deposition with non-nasal breathing was at least twice as high as with nasal breathing (e.g. in the left sinus: $2 \mathrm{mg} / \mathrm{L} v s .1 \mathrm{mg} / \mathrm{L}$ for the SideStream and $3 \mathrm{mg} / \mathrm{L} v s$. $8 \mathrm{mg} / \mathrm{L}$ for the NL11).

\section{Impact of 100-Hz sonic aerosols}

The results concerning the impact of acoustic airflow are shown on Figure 6. The data shown are for the SideStream and the NL11 nebulizers with and without $100-\mathrm{Hz}$ acoustic airflow. No significant differences were noted for the NL20 and Nanoneb nebulizers (data not shown).

Graphs A and B show that acoustic airflow significantly enhanced gentamicin deposition in both the left and right maxillary sinuses for the SideStream and the NL11 nebulizers with non-nasal breathing. With normal or slow nasal breathing, acoustic airflow had no significant effect for any of the four types of nebulizer. 


\section{DISCUSSION}

This study assessed the deposition of a nebulized antibiotic in the maxillary sinuses of a nasal replica while varying three following parameters: particle size, $100 \mathrm{~Hz}$ acoustic effect and breathing patterns.

The 3D nasal replica manufactured for this study was highly consistent with a plastinated anatomical model that closely resembles a healthy subject without nasal congestion (20). Three main families of human nasal casts exist for the study of aerosol deposition: human cadaver models (16), plastic replicas $(12,25)$ and pipe models $(10,26,27)$. However, these casts have several disadvantages such as biosafety and stability over time for cadaver models and lack of fine detail such as maxillary ostium morphology for plastic replicas and pipe models. The replica of the human plastinated model manufactured for this study appears very useful for in vitro characterization of drug deposition in the maxillary sinuses. This model exhibits many desirable technical characteristics such as anatomical features very closely resembling those of in vivo human nasal cavities, coupled with ease of access to the maxillary sinuses, stability over several years, ease of washing, ease of handling and transport, absence of odors and biological safety.

We demonstrated that sonic aerosols using a variety of acoustic airflow (w/wo $100 \mathrm{~Hz}$ ), breathing patterns (nasal vs. non-nasal breathing) and particle size (MMAD in the $230 \mathrm{~nm}$ $9.9 \mu \mathrm{m}$ range) lead to disparate intra-sinus drug deposition. These results clearly demonstrate the ability of gentamicin aerosol to penetrate and the maxillary sinuses. We also confirmed the great efficacy of a $100-\mathrm{Hz}$ acoustic airflow in enhancing drug deposition in the maxillary sinuses. These results confirm the conclusions previously described for a single particle size (2.8 $\mu \mathrm{m}$; NL11) using the human plastinated specimen (9). 
Aerosol deposition within the maxillary sinuses appears to be inversely related to aerosol particle size in the $230 \mathrm{~nm}-2.8 \mu \mathrm{m}$ size range (i.e. all except the largest $9.9 \mu \mathrm{m}$ particles with the NL20 nebulizer). Maximum deposition was achieved with $2.8-\mu \mathrm{m}$ particles using the NL11 nebulizer. We clearly demonstrated non-significant deposition of the smallest particles generated by the Nanoneb device and weak deposition of the 550-nm and 9.9- $\mu \mathrm{m}$ particles generated by the SideStream and NL20 devices respectively. The clear impact of nebulized particle size on the quantity of drug deposited in the maxillary sinuses was observed under non-nasal breathing conditions. In this case, maximum deposition was observed for the 2.8$\mu \mathrm{m}$ particles (NL11 nebulizer) with an acoustic frequency of $100 \mathrm{~Hz}$. It must be noted that for a normalized emitted aerosol fraction, gentamicin deposition of nanometric particles in the maxillary sinuses is enhanced. It suggested the best performance in relation to emitted dose but most of the $230 \mathrm{~nm}$ depositions data were very close to the detection limit and therefore should not be over-interpreted. These results are of great interest for the development of new nano-aerosol devices with improved emitted aerosol fractions. For the moment, the NL11 nebulizer seems to be the best compromise for intrasinus targeting.

Interestingly a recent study also presents data of maxillary sinuses deposition in the percentage range of emitted dose (28). Sinus deposition data are obtained in vivo by means of a radiolabelled aerosol study in patients. Results are approximately 10 times higher than gentamicin deposition obtained in our medication study using a realistic nasal cast. It is however difficult to reach a conclusion because three major parameters change between these studies. 1) Anatomical models are different (in vivo vs. realistic nasal cast). The sinus anatomic features appear to be crucial in predicting the maxillary sinuses deposition even if good consistency has been noticed using realistic nasal cast $(29,30)$ (Durand et al 2012, Le Guellec 2013). Comparison between results of maxillary sinuses deposition obtained using different anatomical model remains difficult. 2) The maxillary sinuses deposition assessment 
was evaluated by a 2D radiolabelled methodology vs. in situ dosage of intrasinusal lavage. 2D radiolabelled quantification is very useful for comparing devices but seems to significantly over-estimate deposition in comparison to other methodologies such as 3D SPECT-CT and intrasinusal lavage (31) (Leclerc et al, in press) and a comparison remains difficult. 3) The nebulization devices are also different and should probably have a strong influence on the deposition (DTF vs. PARI Pharma GmbH).

No differences were observed between normal and slow nasal breathing, even with different particle sizes. By contrast, intrasinus drug deposition was significantly enhanced under nonnasal breathing conditions compared to nasal breathing. These results suggest that the increase in aerosol velocity due to nasal breathing leads to significantly decreased intrasinus drug deposition, underlining the potential value of advocating non-nasal breathing to patients for therapeutic ends.

Our approach is based on the fact that in patients with chronic rhinosinusitis, the ostium of the maxillary sinus is obstructed. Thus, the quantity of antibiotic measured within the maxillary sinus is in fact found at the ostium, which constitutes the "crossroads" of sinus disease (since all gentamicin deposited in the maxillary sinus in our model of a non-congested healthy subject clearly entered the maxillary sinus via the ostium). In addition, for subjects undergoing sinus surgery, meatotomy may enable greater quantities of antibiotic to be deposited in the maxillary sinus than those measured in our model. In either case (operated and unoperated subjects), our results, although obtained in a model of a healthy noncongested subject, are encouraging as regards the potential efficacy of nebulized antibiotics in the treatment of chronic rhinosinusitis, and they demonstrate the relevance of clinical trials on this subject, which should begin in the near future. 
While delivery of effective doses of drug continues to be limited by nebulizer technology, micrometric nebulizers such as the NL11 jet appear to offer the best currently available solution for improved drug delivery in sinus patients. In this conditions addition of a $100 \mathrm{~Hz}$ acoustic airflow is also recommended.

\section{CONCLUSION}

We demonstrated that optimal gentamicin deposition in the maxillary sinuses was obtained with the NL11 nebulizer (MMAD: $2.8 \mu \mathrm{m}$ ) using 100-Hz acoustic airflow and non-nasal breathing. This finding indicates that a specific aerosol pattern should be selected in order to fully enhance intrasinus deposition. Providing patients with specific recommendations concerning the nebulization procedure could thus significantly improve the efficacy of antibiotic treatment.

\section{ACKNOWLEDGEMENTS}

The authors are grateful to the engineering department of Diffusion Technique Française (DTF Medical, Saint-Etienne, France) for their assistance with SolidWorks®.

The authors wish to thank Dr Jean-François Pouget of the Clinique Mutualiste of SaintEtienne for carrying out the CT scans.

The authors would like to acknowledge the financial support of the Regional French Association for Aid to Chronic Respiratory Failure Patients (ARAIR), Saint-Etienne Métropole and the Conseil Général de la Loire.

\section{CONFLICT OF INTEREST}

Marc Durand is a scientific consultant for DTF.

Laurent Vecellio and Sandrine Le Guellec are employees of DTF. 


\section{REFERENCES}

1. Fokkens WJ, Lund VJ, Mullol J, Bachert C, Alobid I, Baroody F, et al. European Position Paper on Rhinosinusitis and Nasal Polyps 2012. Rhinol Suppl. March 2012;(23):3 p preceding table of contents, 1-298.

2. Bhattacharyya N, Grebner J, Martinson NG. Recurrent Acute Rhinosinusitis: Epidemiology and Health Care Cost Burden. Otolaryngol--Head Neck Surg Off J Am Acad Otolaryngol-Head Neck Surg. 25 Oct 2011;

3. Tarhan E, Coskun M, Cakmak O, Çelik H, Cankurtaran M. Acoustic rhinometry in humans: accuracy of nasal passage area estimates, and ability to quantify paranasal sinus volume and ostium size. J Appl Physiol. 8 Jan 2005;99(2):616-623.

4. Deshpande T, Masareddy R, Patil A. Nasal drug delivery-a review. RGUHS J Pharm Sci. 2012;2(1):24-37.

5. Djupesland PG. Nasal drug delivery devices: characteristics and performance in a clinical perspective-a review. Drug Deliv Transl Res. Feb 2013;3(1):42-62.

6. Vaughan WC, Carvalho G. Use of Nebulized Antibiotics for Acute Infections in Chronic Sinusitis. Otolaryngol -- Head Neck Surg. 1 Dec 2002;127(6):558-568.

7. Vecellio L, De Gersem R, Le Guellec S, Reychler G, Pitance L, Le Pennec D, et al. Deposition of aerosols delivered by nasal route with jet and mesh nebulizers. Int $\mathbf{J}$ Pharm. 4 Apr 2011;407(1-2):87-94.

8. Valentine R, Athanasiadis T, Thwin M, Singhal D, Weitzel EK, Wormald P-J. A prospective controlled trial of pulsed nasal nebulizer in maximally dissected cadavers. Am J Rhinol. August 2008;22(4):390-394.

9. Durand M, Pourchez J, Aubert G, Le Guellec S, Navarro L, Forest V, et al. Impact of acoustic airflow nebulization on intrasinus drug deposition of a human plastinated nasal cast: new insights into the mechanisms involved. Int J Pharm. 12 Dec 2011;421(1):6371.

10. Möller W, Schuschnig U, Meyer G, Mentzel H, Keller M. Ventilation and drug delivery to the paranasal sinuses: studies in a nasal cast using pulsating airflow. Rhinology. Sept 2008;46(3):213-220.

11. Kundoor V, Dalby RN. Assessment of nasal spray deposition pattern in a silicone human nose model using a color-based method. Pharm Res. Jan 2010;27(1):30-36.

12. Kelly JT, Prasad AK, Wexler AS. Detailed flow patterns in the nasal cavity. J Appl Physiol Bethesda Md 1985. Jul 2000;89(1):323-337.

13. Janssens HM, de Jongste JC, Fokkens WJ, Robben SG, Wouters K, Tiddens HA. The Sophia Anatomical Infant Nose-Throat (Saint) model: a valuable tool to study aerosol deposition in infants. J Aerosol Med Off J Int Soc Aerosols Med. 2001;14(4):433-441. 
14. Hyo N, Takano H, Hyo Y. Particle deposition efficiency of therapeutic aerosols in the human maxillary sinus. Rhinology. March 1989;27(1):17-26.

15. Saijo R, Majima Y, Hyo N, Takano H. Particle deposition of therapeutic aerosols in the nose and paranasal sinuses after transnasal sinus surgery: a cast model study. Am $\mathbf{J}$ Rhinol. Feb 2004;18(1):1-7.

16. Hilton C, Wiedmann T, St Martin M, Humphrey B, Schleiffarth R, Rimell F. Differential deposition of aerosols in the maxillary sinus of human cadavers by particle size. Am $\mathbf{J}$ Rhinol. August 2008;22(4):395-398.

17. Durand M, Rusch P, Granjon D, Chantrel G, Prades JM, Dubois F, et al. Preliminary study of the deposition of aerosol in the maxillary sinuses using a plastinated model. $\mathbf{J}$ Aerosol Med Off J Int Soc Aerosols Med. 2001;14(1):83-93.

18. Croce C, Fodil R, Durand M, Sbirlea-Apiou G, Caillibotte G, Papon J-F, et al. In vitro experiments and numerical simulations of airflow in realistic nasal airway geometry. Ann Biomed Eng. June 2006;34(6):997-1007.

19. Hagens GV. Impregnation of soft biological specimens with thermosetting resins and elastomers. Anat Rec. 1979;194(2):247-55.

20. Durand M, Pourchez J, Louis B, Pouget JF, Isabey D, Coste A, et al. Plastinated nasal model: a new concept of anatomically realistic cast. Rhinology. March 2011;49(1):3036.

21. Vecellio None L, Grimbert D, Bordenave J, Benoit G, Furet Y, Fauroux B, et al. Residual gravimetric method to measure nebulizer output. J Aerosol Med Off J Int Soc Aerosols Med. 2004;17(1):63-71.

22. Criée CP, Sorichter S, Smith HJ, Kardos P, Merget R, Heise D, et al. Body plethysmography - Its principles and clinical use. Respir Med. Jul 2011;105(7):959-971.

23. Booker R. Interpretation and evaluation of pulmonary function tests. Nurs Stand R Coll Nurs G B 1987. 3 June 2009;23(39):46-56; quiz 58.

24. Flesch JD, Dine CJ. Lung volumes: Measurement, clinical use, and coding. CHEST J. 1 August 2012;142(2):506-510.

25. Schreck S, Sullivan KJ, Ho CM, Chang HK. Correlations between flow resistance and geometry in a model of the human nose. J Appl Physiol. 10 Jan 1993;75(4):1767-1775.

26. Maniscalco M, Sofia M, Weitzberg E, Lundberg JO. Sounding airflow enhances aerosol delivery into the paranasal sinuses. Eur J Clin Invest. Jul 2006;36(7):509-513.

27. Cakmak O, Celik H, Cankurtaran M, Buyuklu F, Ozgirgin N, Ozluoglu LN. Effects of paranasal sinus ostia and volume on acoustic rhinometry measurements: a model study. J Appl Physiol Bethesda Md 1985. Apr 2003;94(4):1527-1535. 
28. Möller W, Schuschnig U, Celik G, Münzing W, Bartenstein P, Häussinger K, et al. Topical Drug Delivery in Chronic Rhinosinusitis Patients before and after Sinus Surgery Using Pulsating Aerosols. PLoS ONE. 11 Sept 2013;8(9):e74991.

29. Durand M, Le Guellec S, Pourchez J, Dubois F, Aubert G, Chantrel G, et al. Sonic aerosol therapy to target maxillary sinuses. Eur Ann Otorhinolaryngol Head Neck Dis. Oct 2012;129(5):244-250.

30. Guellec SL, Pennec DL, Gatier S, Leclerc L, Cabrera M, Pourchez J, et al. Validation of Anatomical Models to Study Aerosol Deposition in Human Nasal Cavities. Pharm Res. 1 Jan 2014;31(1):228-237.

31. Leclerc L, Pourchez J, Prevot N, Vecellio L, Le Guellec S, Cottier M, et al. Assessing sinus aerosol deposition: Benefits of SPECT-CT imaging. Int J Pharm (2014); http://www.sciencedirect.com/science/article/pii/S0378517313011009 


\begin{tabular}{|c|c|c|c|c|}
\hline & MMAD (nm) & GSD & $\begin{array}{c}\text { Emitted aerosol } \\
\text { fraction (\%) }\end{array}$ & $\begin{array}{c}\text { Gentamicin } \\
\text { output mass (mg) }\end{array}$ \\
\hline NL20 & 9900 & 2 & $6.84 \pm 0.29$ & 21.88 \\
\hline NL11 & 2800 & 3.2 & $9.96 \pm 1.72$ & 31.89 \\
\hline SideStream & 550 & 2.1 & $2.06 \pm 0.46$ & 6.6 \\
\hline Nanoneb & 230 & 1.6 & $0.26 \pm 0.04$ & 0.83 \\
\hline
\end{tabular}

Table 1: Aerosol characteristics after $10 \mathrm{~min}$ of nebulization: mass median aerodynamic diameter (MMAD) evaluated using ELPI. Results are also expressed as a percentage of the emitted aerosol fraction and gentamicin output mass (mg). 
A

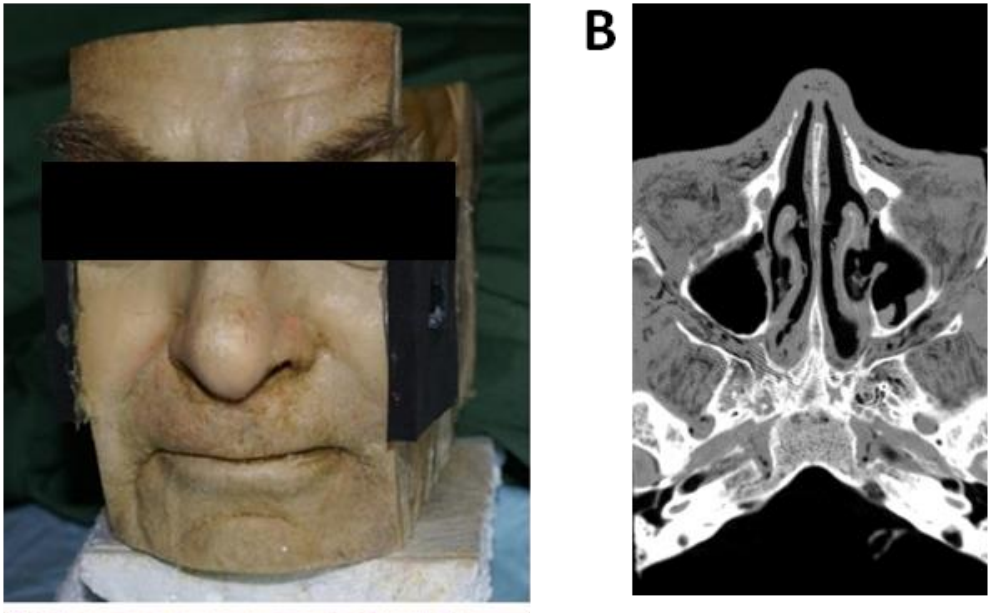

C
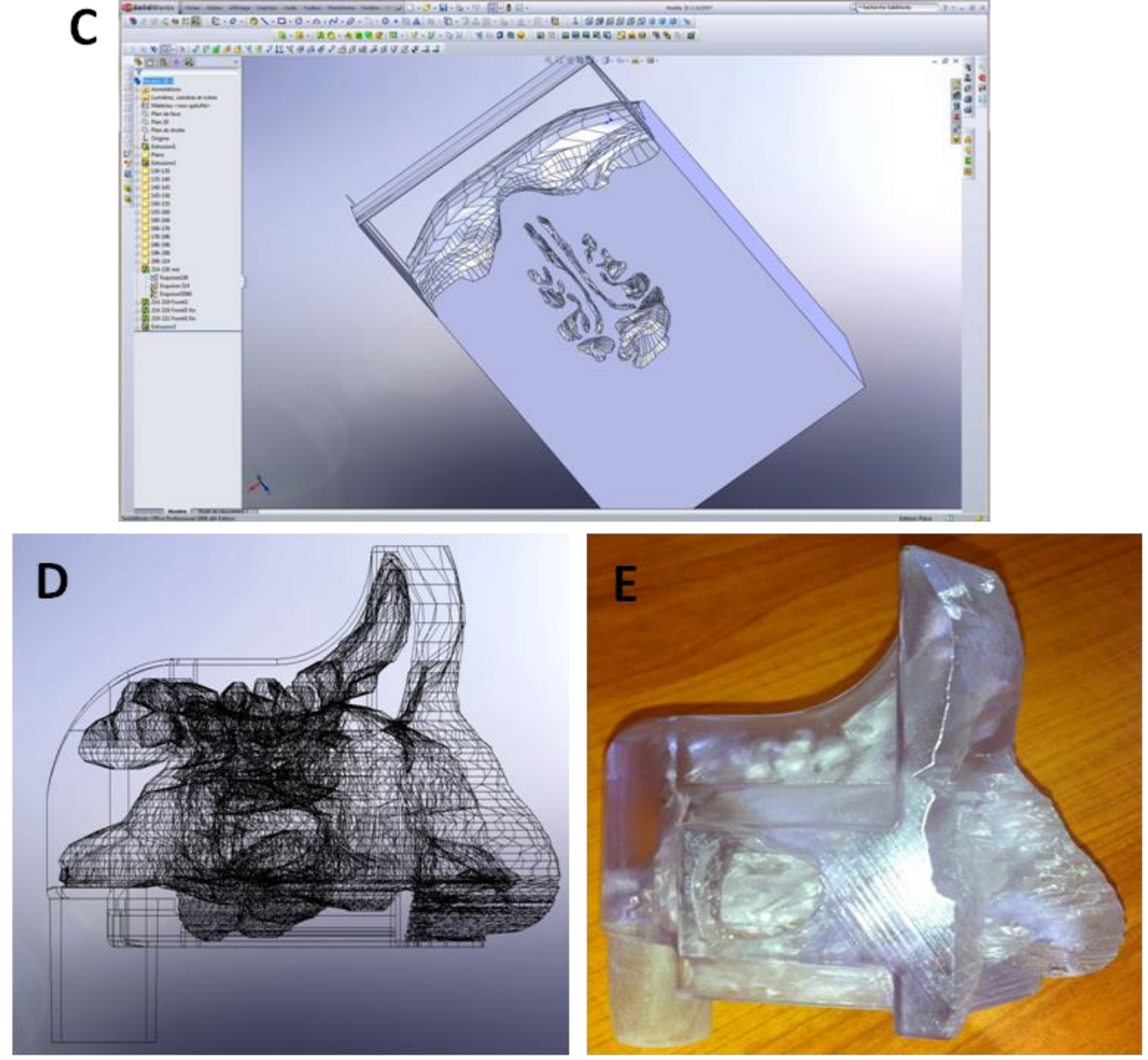

Figure 1: Plastic replica made from the plastinated model. A) Plastinated human specimen B) DICOM scan image - C) SolidWorks ${ }^{\circledR}$ image - D) 3D reconstruction - E) Resin nasal replica. 

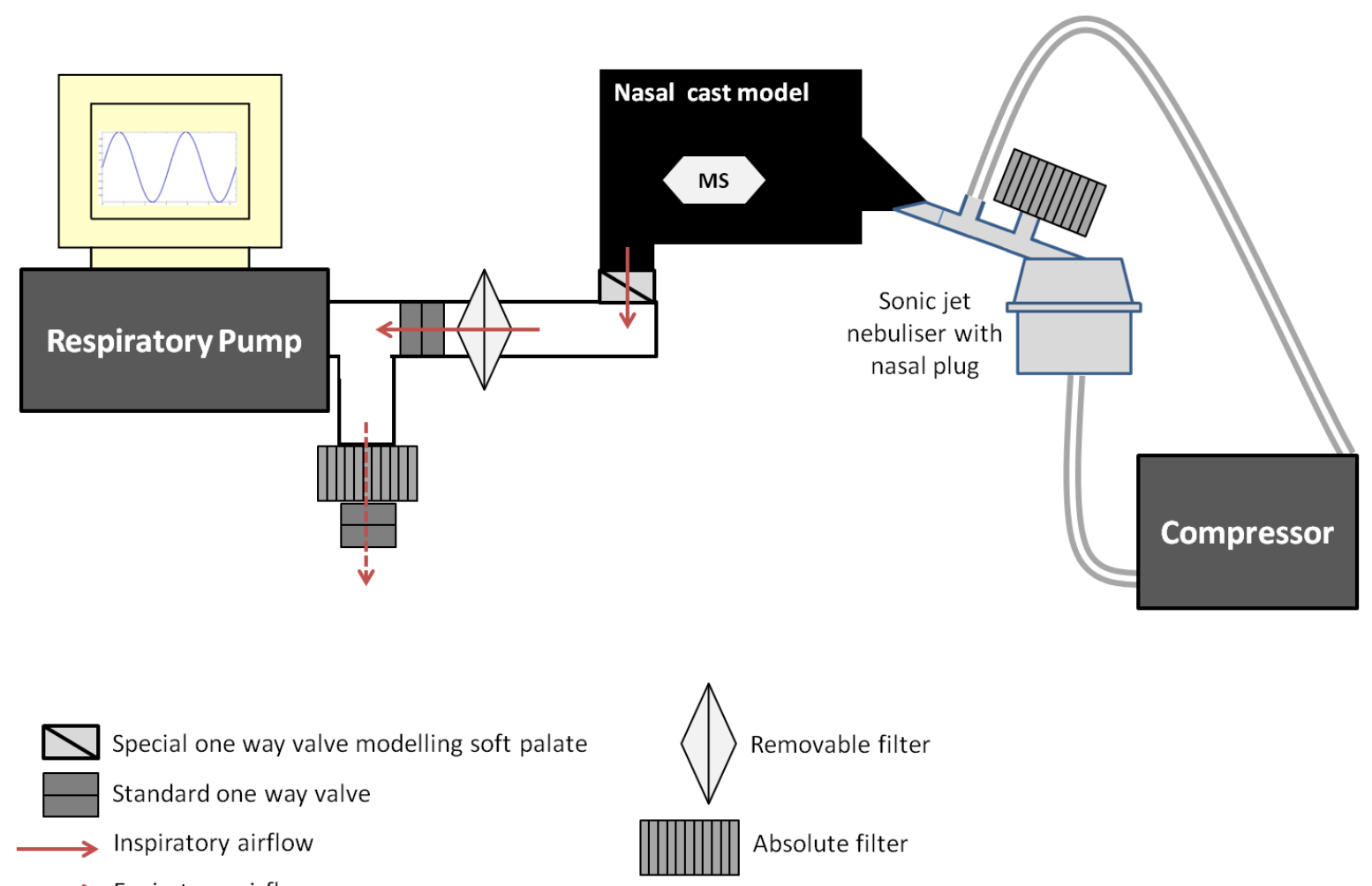

Figure 2: Experimental design for aerosol deposition. 

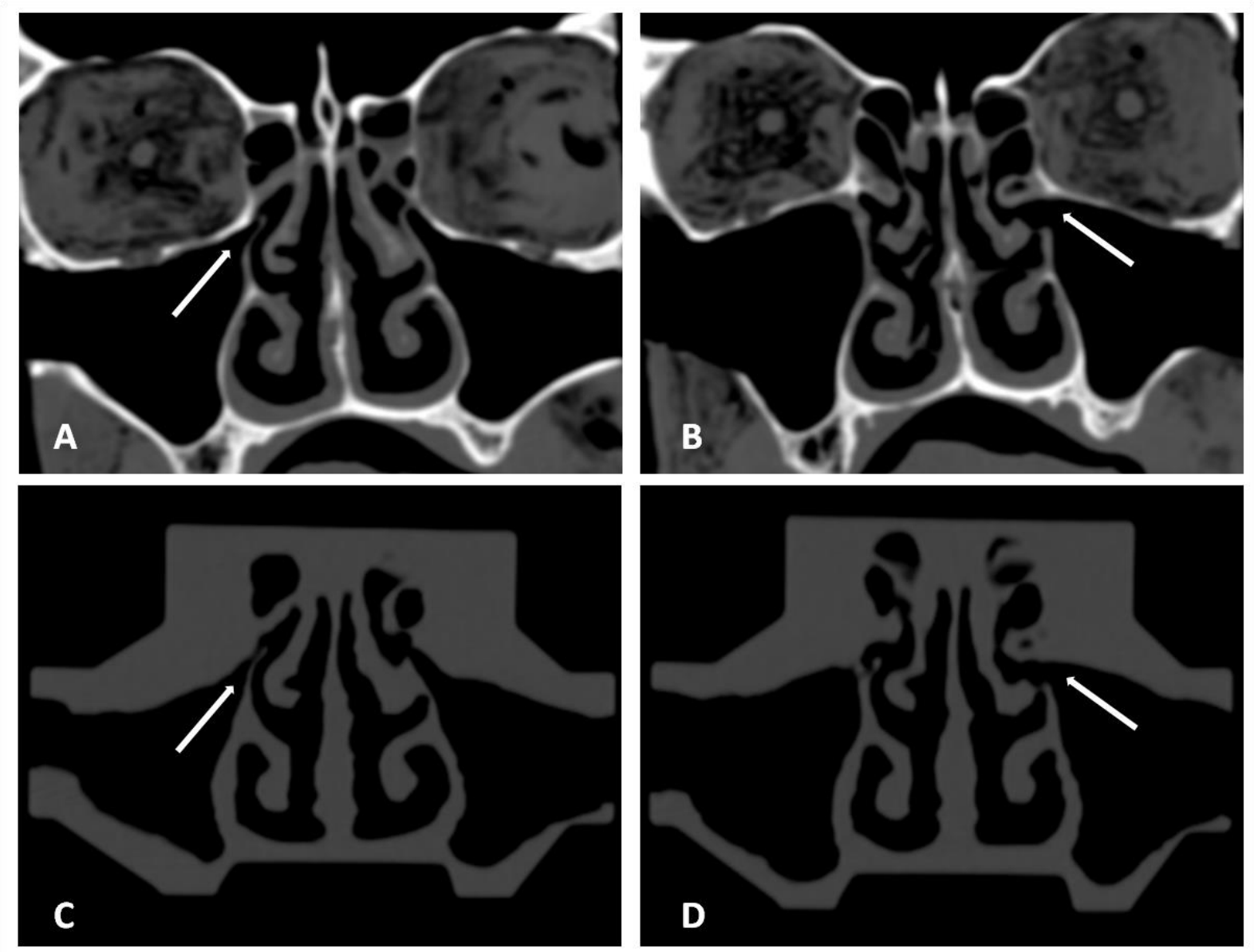

Figure 3: CT scans performed on the plastinated specimen (A and B) and on the plastic nasal replica (C and D). Note preservation of mucosa and different maxillary ostia morphologies (white arrows). 

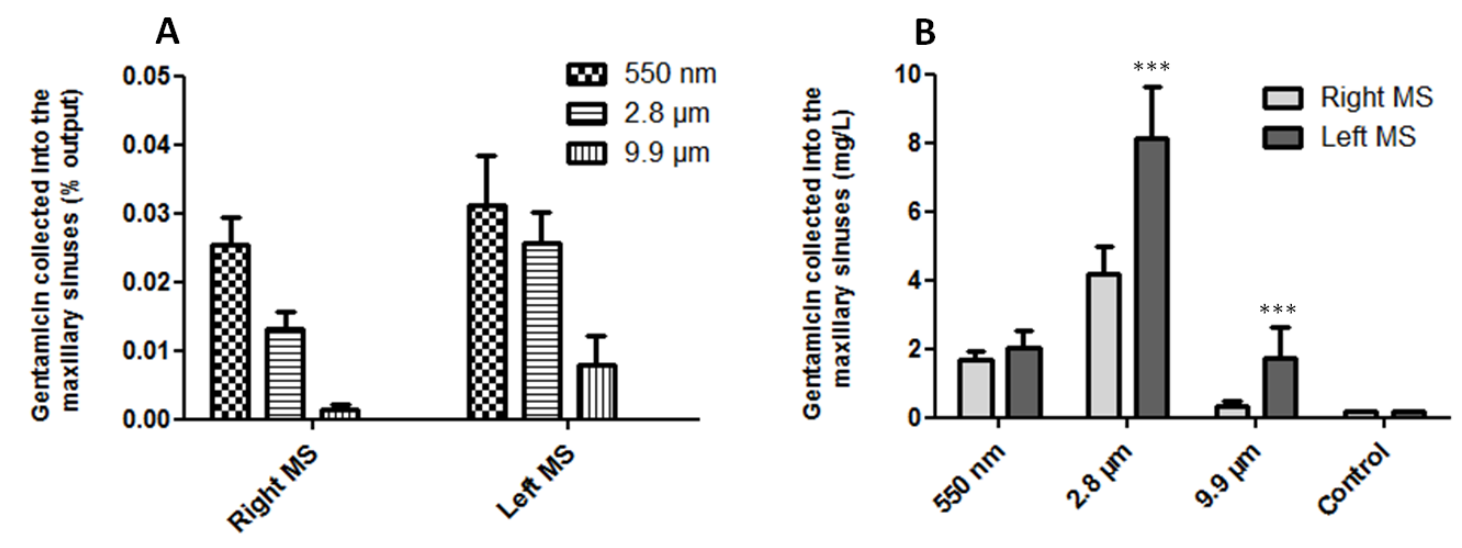

Figure 4: Impact of nebulized particle size (MMAD) and anatomical features such as right vs. left maxillary sinus (MS). A) Amount of nebulized gentamicin collected in the maxillary sinus, expressed as emitted aerosol fraction. B) Amount of nebulized gentamicin collected in the maxillary sinus, in mg/L. Experiments conducted under non-nasal breathing conditions with $100 \mathrm{~Hz}$ acoustic airflow. Nebulized physiological saline solution was used as the control $(\mathrm{n}=7$ for each data set, mean \pm SEM, $\mathrm{p}<0.05)$.
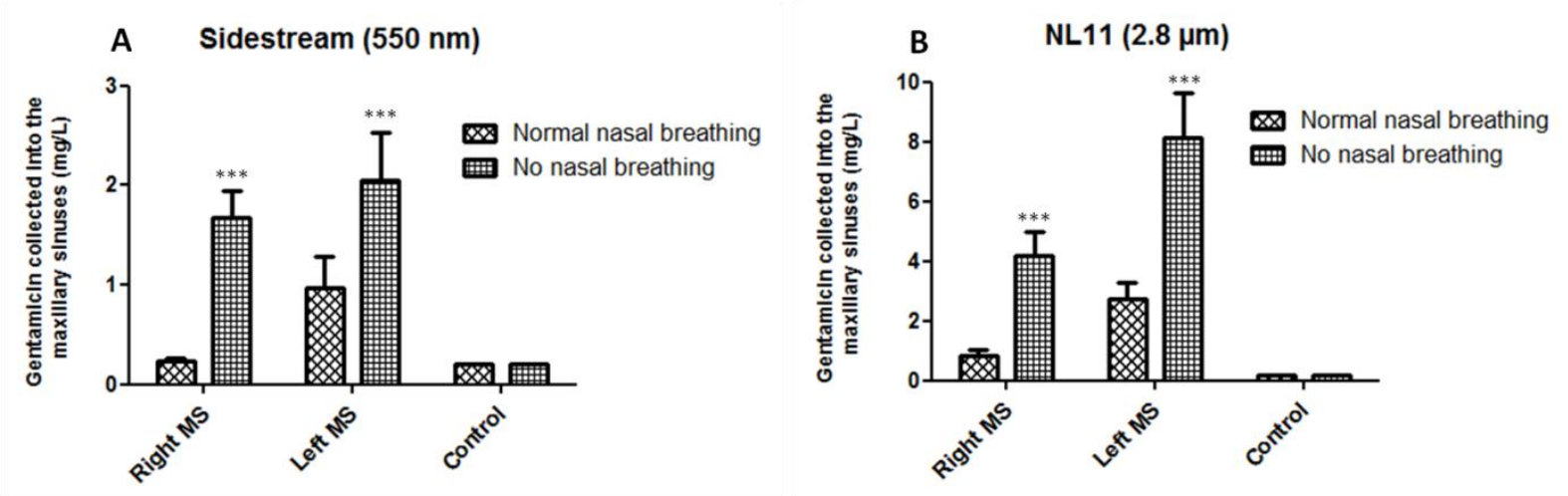

Figure 5: Impact of breathing patterns on nebulized gentamicin collected in the maxillary sinus (MS) in mg/L. Experiments conducted with $100 \mathrm{~Hz}$ acoustic airflow. A) SideStream nebulizer (MMAD: $550 \mathrm{~nm}$ ). B) NL11 nebulizer (MMAD: $2.8 \mu \mathrm{m}$ ). Nebulized physiological saline solution was used as the control $(\mathrm{n}=7$ for each data set, mean \pm SEM, $\mathrm{p}<0.05)$. 

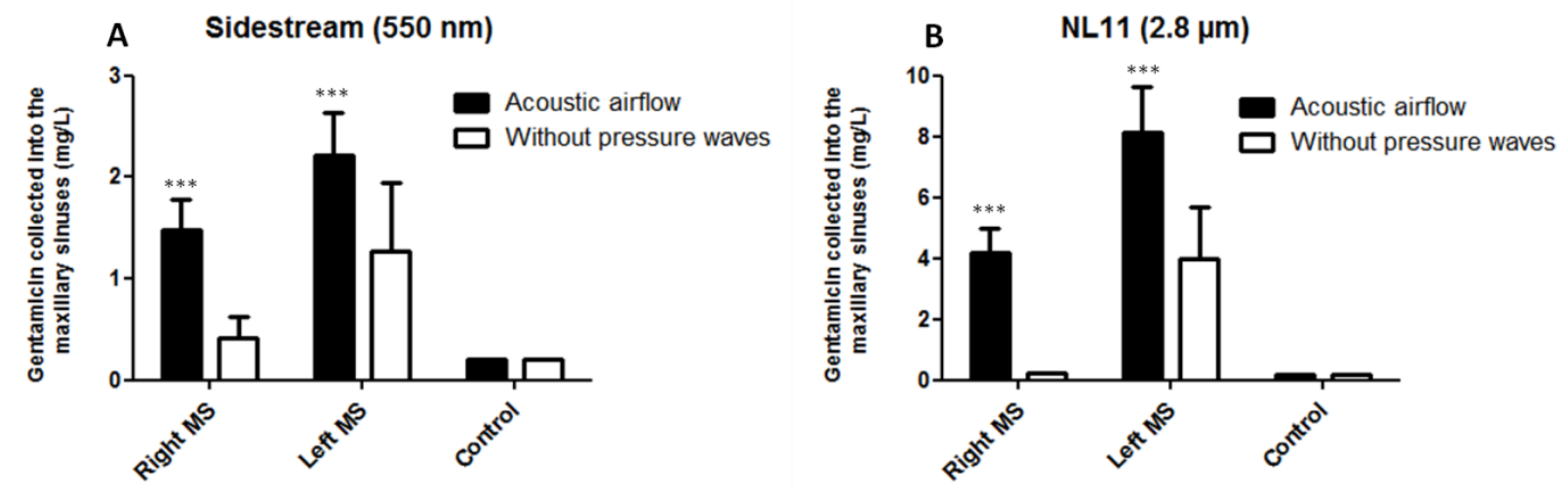

Figure 6: Impact of $100 \mathrm{~Hz}$ acoustic airflow on nebulized gentamicin collected in the maxillary sinus (MS) in mg/L. Experiments conducted under non-nasal breathing conditions. A) SideStream nebulizer (MMAD: $550 \mathrm{~nm}$ ). B) NL11 nebulizer (MMAD: $2.8 \mu \mathrm{m}$ ). Nebulized physiological saline solution was used as the control $(n=7$ for each data set, mean \pm SEM, $\mathrm{p}<0.05)$. 


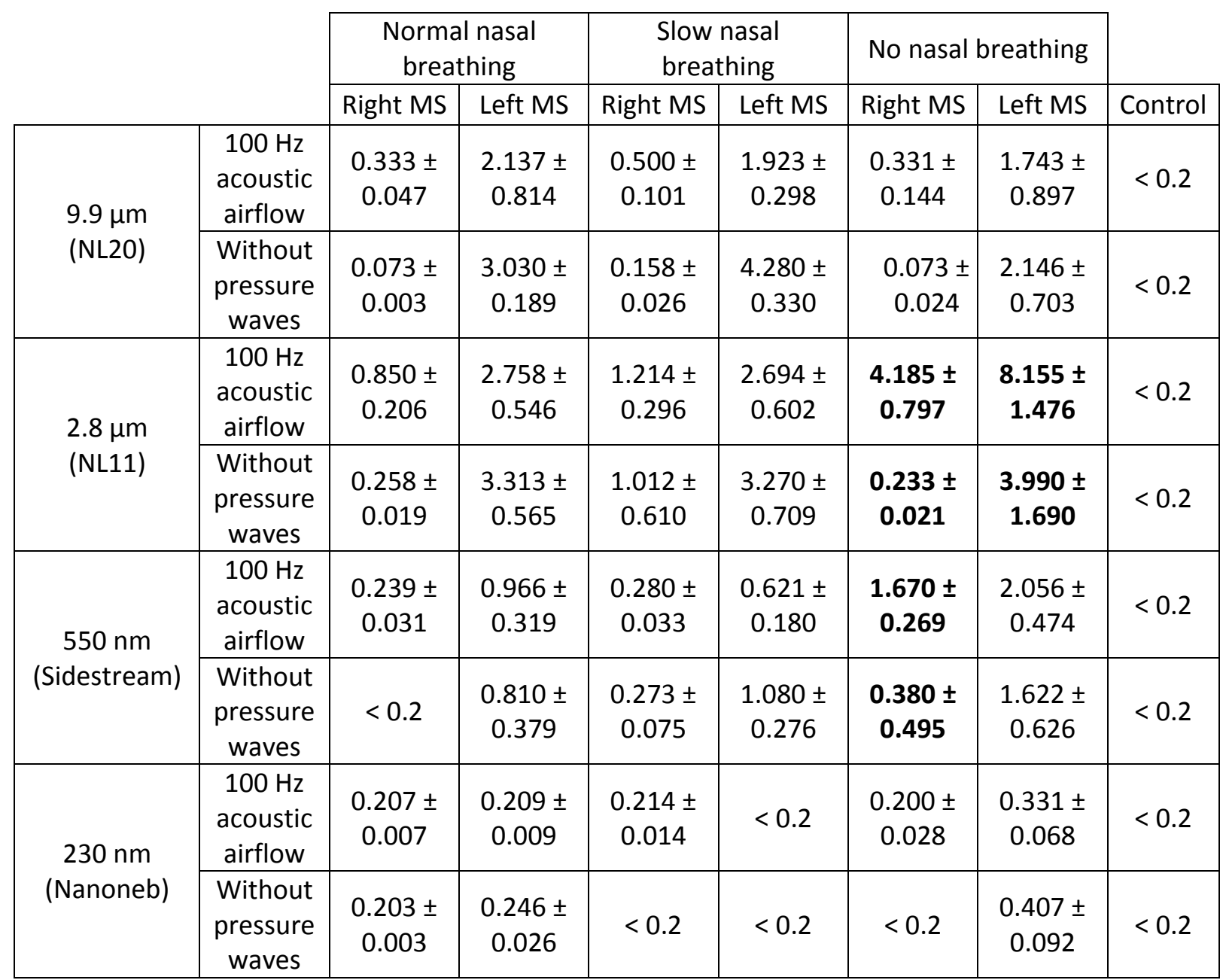

Supplementary Table I: Summary table of nebulized gentamicin collected in the maxillary sinus (MS) in mg/L. Physiological saline solution was nebulized as the control $(\mathrm{n}=7$ for each data set, mean \pm SEM, $\mathrm{p}<0.05)$. Significant differences between "100 Hz acoustic airflow" and "Without pressure waves" (***) are highlighted in bold in the table (ANOVA test). 


\begin{tabular}{|c|c|c|c|c|c|c|c|}
\hline & \multicolumn{2}{|c|}{ Normal Breathing } & \multicolumn{2}{|c|}{ Slow Breathing } & \multicolumn{2}{|c|}{ No Nasal Breathing } \\
\hline & & Right MS & Left MS & Right MS & Left MS & Right MS & Left MS \\
\hline \multirow{2}{*}{$\begin{array}{l}9.9 \mu \mathrm{m} \\
\text { (NL20) }\end{array}$} & $\begin{array}{c}100 \mathrm{~Hz} \\
\text { acoustic } \\
\text { airflow }\end{array}$ & $\begin{array}{l}0.00152 \pm \\
0.00037\end{array}$ & $\begin{array}{l}0.00977 \pm \\
0.00644\end{array}$ & $\begin{array}{l}0.00229 \pm \\
0.00092\end{array}$ & $\begin{array}{l}0.00879 \pm \\
0.00236\end{array}$ & $\begin{array}{l}0.00151 \pm \\
0.00197\end{array}$ & $\begin{array}{l}0.00797 \pm \\
0.01085\end{array}$ \\
\hline & \begin{tabular}{|l} 
Without \\
pressure \\
waves
\end{tabular} & $\begin{array}{l}0.00034 \pm \\
0.00003\end{array}$ & $\begin{array}{l}0.01385 \pm \\
0.00150\end{array}$ & $\begin{array}{l}0.00072 \pm \\
0.00026\end{array}$ & $\begin{array}{l}0.02754 \pm \\
0.01391\end{array}$ & $\begin{array}{l}0.00033 \pm \\
0.00029\end{array}$ & $\begin{array}{l}0.00981 \pm \\
0.00908\end{array}$ \\
\hline \multirow{2}{*}{$\begin{array}{l}2.8 \mu \mathrm{m} \\
\text { (NL11) }\end{array}$} & $\begin{array}{c}100 \mathrm{~Hz} \\
\text { acoustic } \\
\text { airflow } \\
\end{array}$ & $\begin{array}{l}0.00267 \pm \\
0.00171\end{array}$ & $\begin{array}{l}0.00715 \pm \\
0.00407\end{array}$ & $\begin{array}{l}0.00381 \pm \\
0.00245\end{array}$ & $\begin{array}{l}0.00652 \pm \\
0.00479\end{array}$ & $\begin{array}{l}0.01313 \pm \\
0.00902\end{array}$ & $\begin{array}{l}0.02558 \pm \\
0.01670\end{array}$ \\
\hline & $\begin{array}{l}\text { Without } \\
\text { pressure } \\
\text { waves }\end{array}$ & $\begin{array}{l}0.00081 \pm \\
0.00019\end{array}$ & $\begin{array}{l}0.01472 \pm \\
0.00531\end{array}$ & $\begin{array}{l}0.00317 \pm \\
0.00605\end{array}$ & $\begin{array}{l}0.00879 \pm \\
0.00630\end{array}$ & $\begin{array}{l}0.00073 \pm \\
0.00021\end{array}$ & $\begin{array}{l}0.01252 \pm \\
0.00750\end{array}$ \\
\hline \multirow{2}{*}{$\begin{array}{c}550 \mathrm{~nm} \\
\text { (Sidestream) }\end{array}$} & $\begin{array}{c}100 \mathrm{~Hz} \\
\text { acoustic } \\
\text { airflow }\end{array}$ & $\begin{array}{l}0.00361 \pm \\
0.00124\end{array}$ & $\begin{array}{l}0.01463 \pm \\
0.01277\end{array}$ & $\begin{array}{l}0.00424 \pm \\
0.00130\end{array}$ & $\begin{array}{l}0.00942 \pm \\
0.00720\end{array}$ & $\begin{array}{l}0.02530 \pm \\
0.01079\end{array}$ & $\begin{array}{l}0.05357 \pm \\
0.04054\end{array}$ \\
\hline & \begin{tabular}{|c|} 
Without \\
pressure \\
waves
\end{tabular} & NC & $\begin{array}{l}0.01227 \pm \\
0.01520\end{array}$ & $\begin{array}{l}0.00413 \pm \\
0.00299\end{array}$ & $\begin{array}{l}0.01935 \pm \\
0.01224\end{array}$ & $\begin{array}{l}0.00582 \pm \\
0.00739\end{array}$ & $\begin{array}{l}0.02458 \pm \\
0.02122\end{array}$ \\
\hline \multirow{2}{*}{$\begin{array}{c}230 \mathrm{~nm} \\
\text { (Nanoneb) }\end{array}$} & $\begin{array}{c}100 \mathrm{~Hz} \\
\text { acoustic } \\
\text { airflow } \\
\end{array}$ & $\begin{array}{l}0.02496 \pm \\
0.00228\end{array}$ & $\begin{array}{l}0.02513 \pm \\
0.00273\end{array}$ & $\begin{array}{l}0.02575 \pm \\
0.00496\end{array}$ & NC & $\begin{array}{l}0.02410 \pm \\
0.00888\end{array}$ & $\begin{array}{l}0.03993 \pm \\
0.02155\end{array}$ \\
\hline & $\begin{array}{l}\text { Without } \\
\text { pressure } \\
\text { waves }\end{array}$ & $\begin{array}{l}0.02444 \pm \\
0.00091\end{array}$ & $\begin{array}{l}0.02960 \pm \\
0.00820\end{array}$ & NC & NC & NC & $\begin{array}{l}0.04905 \pm \\
0.02942\end{array}$ \\
\hline
\end{tabular}

Supplementary Table II: Summary table of nebulized gentamicin collected in the maxillary sinus (MS). Results are expressed in percentage of the emitted dose $(\mathrm{NC}=$ Not Calculated $)$. Physiological saline solution was nebulized as the control $(n=7$ for each data set, mean \pm SEM, $\mathrm{p}<0.05)$. 